\title{
Advancement of Rail Ballast Testing Methodologies and Design Implications
}

\author{
Buddhima Indraratna, Ph.D, F.ASCE, ${ }^{1}$ Trung Ngo, Ph.D, M.ASCE, ${ }^{2}$ Cholachat \\ Rujikiatkamjorn, Ph.D, M.ASCE, ${ }^{3}$ and Fernanda Ferreira, Ph.D. ${ }^{4}$
}

${ }^{1}$ ARC Training Centre for Advanced Technologies in Rail Track Infrastructure (ITTC-Rail), Centre for Geomechanics and Railway Engineering(CGRE), University of Wollongong Australia, Northfields Ave, Wollongong NSW 2522; e-mail: indra@uow.edu.au

${ }^{2}$ ARC Training Centre for Advanced Technologies in Rail Track Infrastructure (ITTC-Rail), Centre for Geomechanics and Railway Engineering(CGRE), University of Wollongong Australia, Northfields Ave, Wollongong NSW 2522; e-mail: trung@uow.edu.au

${ }^{3}$ ARC Training Centre for Advanced Technologies in Rail Track Infrastructure (ITTC-Rail), Centre for Geomechanics and Railway Engineering(CGRE), University of Wollongong Australia, Northfields Ave, Wollongong NSW 2522; e-mail: cholacha@uow.edu.au

${ }^{4}$ Construct-GEO, Faculty of Engineering, University of Porto, R. Dr. Roberto Frias, 4200-465 Porto, Portugal; e-mail: fbf@fe.up.pt

\begin{abstract}
Given the limited capacity of available railway tracks in Australia to sustain increasingly faster and heavier trains, the development of innovative and sustainable ballasted tracks is essential for Australian transport infrastructure. Upon repeated train loading, ballast aggregates become degraded and fouled owing to the intrusion of external fines either from the subbase or surface, which decreases track drainage potentially leading to track instability. This paper reviews some advancements in testing methodologies and design implications of ballasted tracks stabilized with artificial inclusions, including geocomposites, energy absorbing rubber mats and end-of-life tires. Measured test data shows that the use of these waste rubber products and geosynthetics provides an appropriate solution for mitigating unacceptable track degradation and for improving sustainable track alignment, apart from reducing the thickness of the ballast layer. Field monitoring data from fully instrumented tracks constructed at Singleton, Australia is presented and discussed. The outcomes of this study contribute to a better understanding of the performance of reinforced ballasted tracks, which will be imperative for the development of more efficient and cost-effective track designs with enhanced safety and passenger comfort.
\end{abstract}




\section{INTRODUCTION}

Ballast is the key foundation material placed underneath sleepers to offer structural support against dynamic and impact loads applied by fast running trains (Selig and Waters 1994; Indraratna et al. 2011). The ballast layer is commonly composed of crushed granular aggregates having a typical thickness of $300 \mathrm{~mm}$ and is placed underneath the track super-structure and above the capping (subballast) or subgrade. The deterioration (breakage) of ballast is one of the major contributing factors which affect the stability and longevity of railway foundations (Tutumluer et al. 2012; Sun et al. 2018; Le Pen et al. 2011; Ngo et al. 2017). The adoption of various forms of geosynthetic inclusions, such as geogrids and rubber energy absorbing drainage sheets (READS) produced from recycled tires to reduce the plastic deformation and breakage of ballast has become increasingly popular worldwide (Navaratnarajah et al. 2018; Abadi et al. 2019; Indraratna et al. 2016). These synthetic inclusions eliminate hard interfaces between ballast aggregates and concrete sleepers or the underlying formation soils, and allow the aggregates to bed into the relatively softer pads, thus increasing the contact surface area of the ballast and reducing ballast stresses. However, studies that analyze how well these synthetic inclusions can improve the performance of ballasted tracks are still limited. This paper reviews recent research work undertaken at the University of Wollongong Australia (UOW) using large-scale test facilities, field investigations and computational modeling to evaluate the ability of artificial inclusions to reduce ballast degradation and associated deformation.

\section{LABORATORY TESTING}

\section{Behavior of ballast subjected to monotonic and cyclic loadings}

Past studies have been carried out to investigate the effects of the loading characteristics (i.e. monotonic or cyclic loads) on the shear stress-strain responses of railway ballast (Lackenby et al. 2007; Sun et al. 2018; McDowell and Li 2016, Powrie et al. 2007, Biabani et al. 2016, among others). Based on an extensive laboratory testing program, the volumetric strains of ballast under monotonic and cyclic loading conditions and at different confining pressures have been evaluated, as shown in Figure 1. Although similar ballast materials were tested in the same large-scale triaxial test apparatus, they showed different volumetric strain behaviors when subjected to different loading conditions. It is observed that dilation (volumetric increase) occurs in the ballast specimens under monotonic loads for most confining pressures. However, those ballast specimens subjected to cyclic loads under a confining pressure higher than $30 \mathrm{kPa}$ experience significant compression. This could be due to the re-orientation and re-arrangement of particles induced by cyclic loading, creating a denser (compressing) or looser (dilating) packing assembly (Indraratna and Ngo 2018). Those ballast assemblies subjected to a low confining pressure show mainly dilative response, whereas the reverse happens for ballast specimens under higher confining pressures subjected to cyclic loading. 

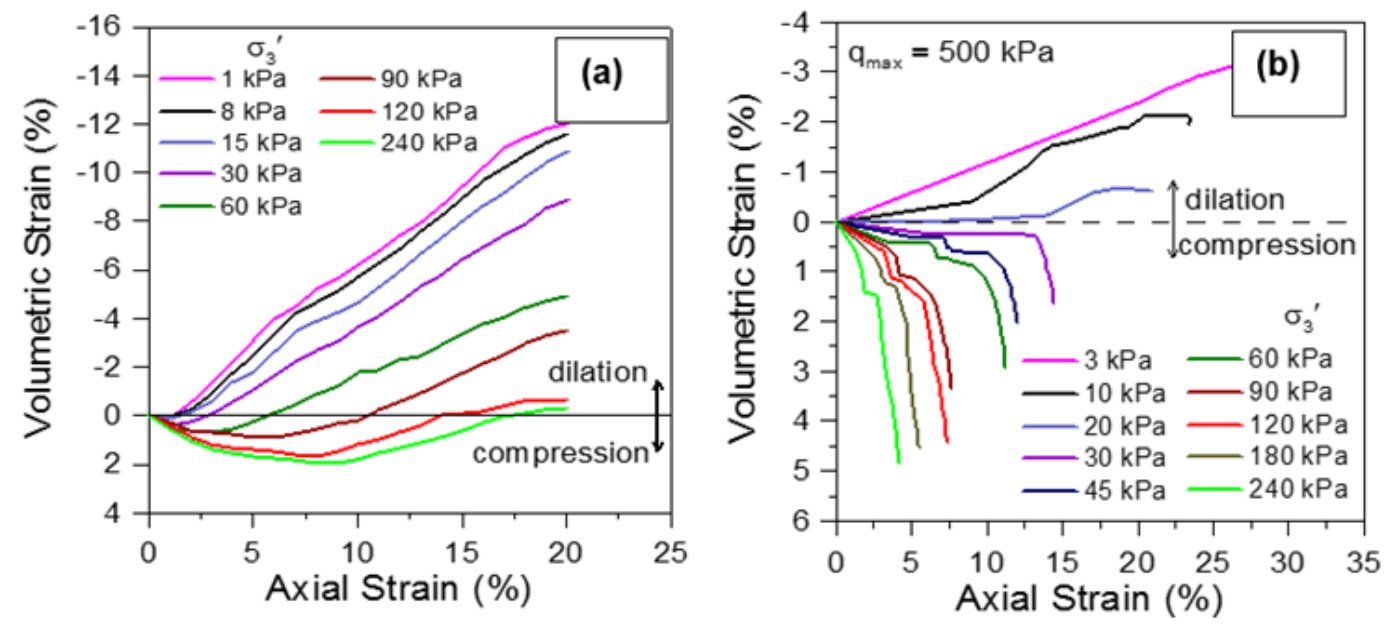

\section{Figure 1. Volumetric strains of ballast tested under: (a) monotonic loading; (b) cyclic loading (modified after Indraratna et al. 2018).}

\section{Geosynthetics-ballast interface shear strength}

The influence of geogrid geometry and aperture size on the interface behavior of a geogridreinforced ballast assembly has been investigated by Indraratna et al. (2012). In this study, seven types of geosynthetics $(G 1-G 7)$ having square, triangular and rectangular opening geometry and varied aperture sizes $(36-70 \mathrm{~mm})$ were tested under different normal stresses $\left(\sigma_{n}=26-61 \mathrm{kPa}\right)$, using a large-scale direct shear test device $(300 \mathrm{~mm} \times 300 \mathrm{~mm} \times 200 \mathrm{~mm})$. The improvement in terms of shear strength of a ballast-geogrid composite assembly can be quantified by an interface efficiency factor $(\alpha)$, which is defined as the ratio of the peak shear stress (shear strength) of the interface to the internal shear strength of the ballast aggregates as: $\alpha=\tan (\delta) / \tan (\varphi)$; where, $\delta$ : apparent friction angle of the geogrid-ballast interface; and $\varphi$ : friction angle of ballast.

The role of geogrid aperture size $(A)$ on the peak shear strength of the ballast-geogrid interface has been evaluated as a function of the ratio $A / D_{50}\left(D_{50}\right.$ : median ballast particle size $)$. Measured data shows that $\alpha$ increases with $A / D_{50}$ until it attains a maximum value of 1.16 at $A / D_{50}$ of about 1.2. Subsequently, $\alpha$ decreases towards 1.0 as $A / D_{50}$ approaches 2.5 . The value of $\alpha<1$ indicates an ineffective interaction (interlocking) with ballast particles, whereas $\alpha>1$ implies an improved interlocking that may help to raise the shear strength. It is noted that the ratio $A / D_{50}$ corresponding to $\alpha=1$ represents the minimum condition needed to generate the beneficial effect of the geogrid reinforcement. Based on the variations of $\alpha$, an optimum interlocking zone can be formed where the $A / D_{50}$ ratio ranges from 0.95 to 1.2 . This study also shows that the maximum and minimum geogrid aperture sizes leading to values of $\alpha>1$ (i.e. enhanced shear strength) can be taken as $2.50 D_{50}$ and $0.95 D_{50}$, respectively.

\section{Use of recycled rubber mats under impact loading}

Rail and wheel defects such as dipped rails, wheel flats, rail corrugations and imperfect rail welds result in large impact loads being imparted onto the rail track sub-structure. Impact loads may also occur at transitions zones due to abrupt changes in track stiffness (e.g. road crossings, concrete 
bridge decks, tunnels), which leads to fast deterioration of the track sub-structure and implies the need for more frequent maintenance (Nimbalkar and Indraratna 2016, Ferreira and Indraratna 2018, Ngo et al. 2018). A large-scale impact test equipment(Fig. 2a) designed and built at the UOW (Kaewunruen and Remennikov 2009) was used to study the performance of a ballast assembly stabilized by rubber energy absorbing drainage sheets made from recycled tires (Fig. 2b) when subjected to repeated impact loading. The test apparatus can accommodate a ballast assembly within a working area of $1800 \times 1500 \mathrm{~mm}$. During the tests, transient impact forces were recorded by a dynamic load cell (capacity of $1200 \mathrm{kN}$ ) installed on the free-fall hammer and connected to a data logging system. A piezoelectric accelerometer was attached to the ballast specimen to measure accelerations and a high-speed camera was used to monitor the impactinduced deformations. The hammer was positioned at varying drop heights, $h_{d}=100-300 \mathrm{~mm}$, which were chosen to produce dynamic loads similar to those generated by typical dipped rail joints or wheel flats, as measured in previous field trials (Indraratna et al. 2014). An automatic triggering system was used for data recording purposes, where the signal obtained during the hammer free-fall was set to an acquisition frequency of $2000 \mathrm{~Hz}$. All tests were deemed complete after fifteen hammer releases $(\mathrm{N}=15)$ due to the attenuation of incremental ballast deformations.
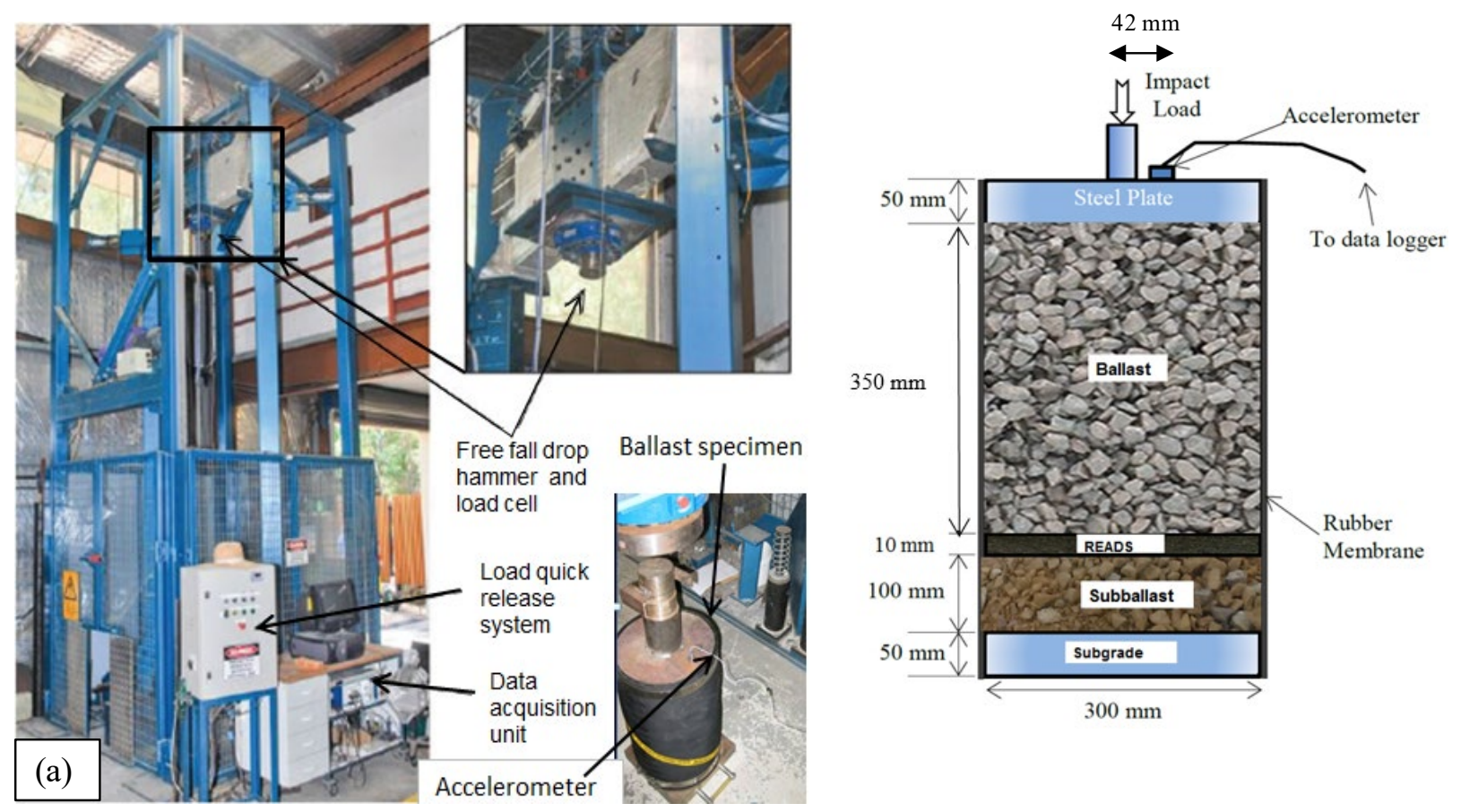

(b)

Figure 2. (a) Drop weight impact test device; (b) schematic diagram of a ballast specimen. The variations of the vertical displacements of ballast specimens (placed over stiff subgrade) during various drops and under a fixed drop height, $h_{d}=150 \mathrm{~mm}$ are presented in Figure 3. It is noted that, upon impact, ballast specimens experience a maximum vertical settlement and then move back to a permanent deformation in approximately $110 \mathrm{~ms}$. The inclusion of the rubber mat 
(READS) leads to reduced peak and residual vertical displacements of ballast. The maximum vertical displacements after the $15^{\text {th }}$ drop, with and without the inclusion of the recycled rubber mat are measured as about $77 \mathrm{~mm}$ and $85 \mathrm{~mm}$, respectively, with corresponding permanent vertical displacements of about $64 \mathrm{~mm}$ and $74 \mathrm{~mm}$. It is observed that the presence of the rubber mat increases the elastic range of displacements before plastic (i.e. irrecoverable) deformation of ballast can occur. The installation of the READS beneath the ballast is also beneficial for enhancing the ballast contacts, thereby providing better load distributions.
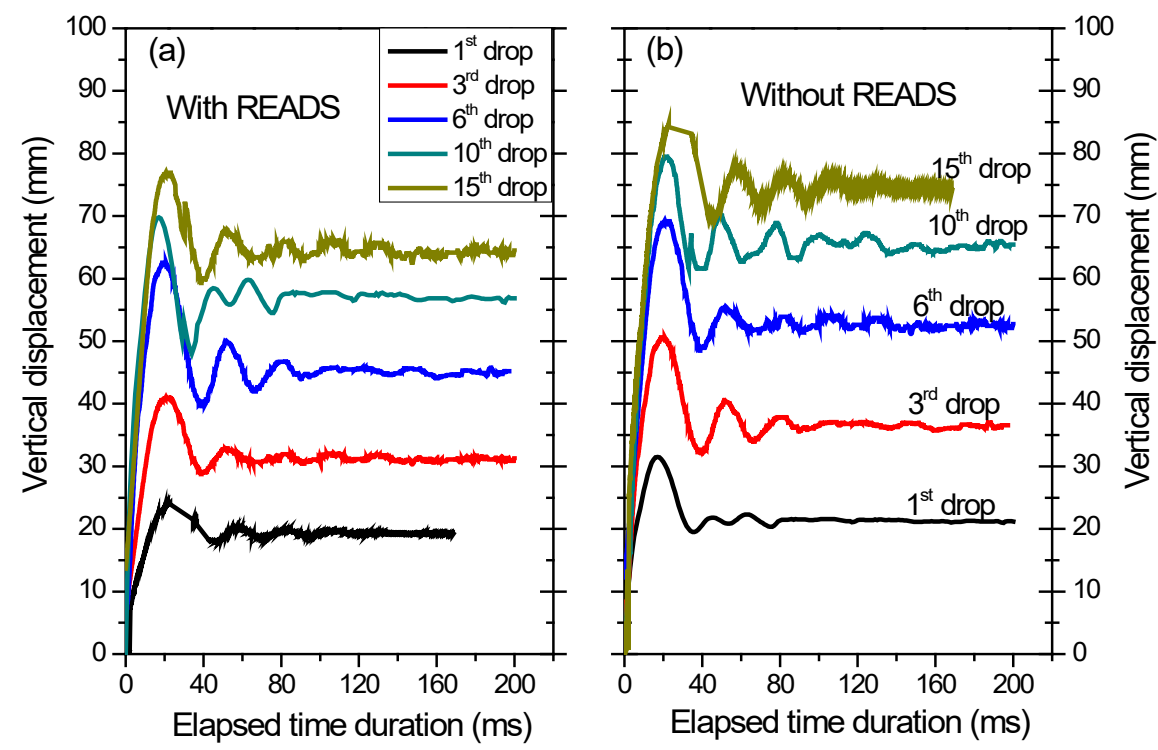

Figure 3. Measured vertical displacement of ballast assemblies placed over stiff subgrade at different drops: (a) with READS; (b) without READS (modified after Ngo et al. 2019 - with permission from Elsevier).

The measured accelerations of ballast specimens placed on soft and stiff subgrades under $h_{d}=100 \mathrm{~mm}$ and $N=10$ (with and without READS) are shown in Figure 4. It is seen that the READS decrease the peak accelerations and help to quickly attenuate the vibration. For the stiff subgrade, the peak accelerations were approximately 112g (with READS) and 170g (without READS). For the soft subgrade, the peak accelerations were about $72 \mathrm{~g}$ (with READS) and $117 \mathrm{~g}$ (without READS). The accelerations of ballast measured under stiff subgrade conditions were higher than those for the case of soft subgrade; and this is reflected by greater vibration magnitudes. The laboratory test data implied that the use of recycled rubber mats can increase passenger comfort thanks to vibration reduction, as well as contribute to more economical track maintenance associated with the reduction in ballast breakage. More details on how the use of READS can contribute to reduced vibration and prevent excessive ballast degradation and deformation can be found in the paper by Ngo et al. (2019). 

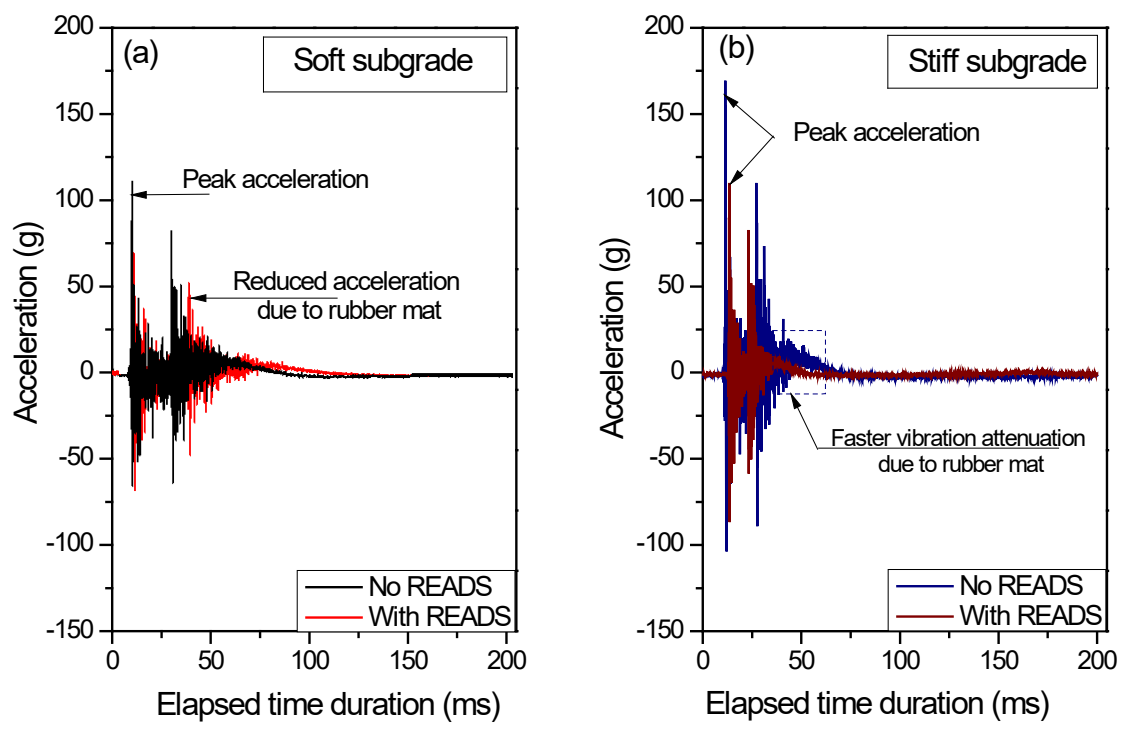

Figure 4. Measured acceleration of ballast under a drop height of $h_{d}=100 \mathrm{~mm}$ : (a) soft subgrade; (b) stiff subgrade (modified after Ngo et al. 2019 - with permission from Elsevier).

\section{APPLICATION OF GEOSYNTHETICS AND RUBBER MATS IN FIELD TRACKS}

Experimental sections of tracks were built in Bulli and Singleton (NSW, Australia) to assess the track performance improvement resulting from the use of geosynthetics and rubber mats (Indraratna et al. 2010; Nimbalkar and Indraratna 2016). The experimental sections were monitored as follows: (i) lateral and vertical ballast stresses were recorded by pressure cells; (ii) horizontal and vertical displacements of ballast were obtained by digital displacement transducers and settlement pegs installed at sleeper-ballast and ballast-capping interfaces, respectively. Field measurement data showed that the peak cyclic vertical stresses $\left(\sigma_{v}\right)$ decreased significantly at depths of $300 \mathrm{~mm}$ and $450 \mathrm{~mm}$ (i.e. below the ballast and capping layers, respectively), in comparison with those measured under the sleeper. However, the lateral stresses $\left(\sigma_{l}\right)$ only reduced marginally with depth (Indraratna et al. 2010). Most of the maximum cyclic vertical stresses were measured as approximately $230 \mathrm{kPa}$, but there was one peak of $\sigma_{v}$ reaching $415 \mathrm{kPa}$. This was later found to be caused by a wheel flat, demonstrating that much larger stresses are generated in the presence of wheel defects, which inevitably exacerbates track damage. The permanent vertical strains of ballast were measured at certain time intervals by surveying the changes in the level of the settlement pegs. The evolutions of the average ballast settlements with time are illustrated in Figure $5 \mathrm{a}$. The data indicate that the geosynthetic reinforcement reduces the vertical, $S_{v}$ and lateral, $S_{l}$ displacements of fresh ballast by about $30 \%$ and $45 \%$, respectively, as well as the vertical and lateral displacements of recycled (used) ballast by about 10\% and 12\% (Indraratna et al. 2010). In addition, the inclusion of rubber mats (energy-absorbing mats) resulted in attenuated ballast degradation (Fig. 5b), as inferred from the Singleton track measurements (Nimbalkar and Indraratna 2016). 


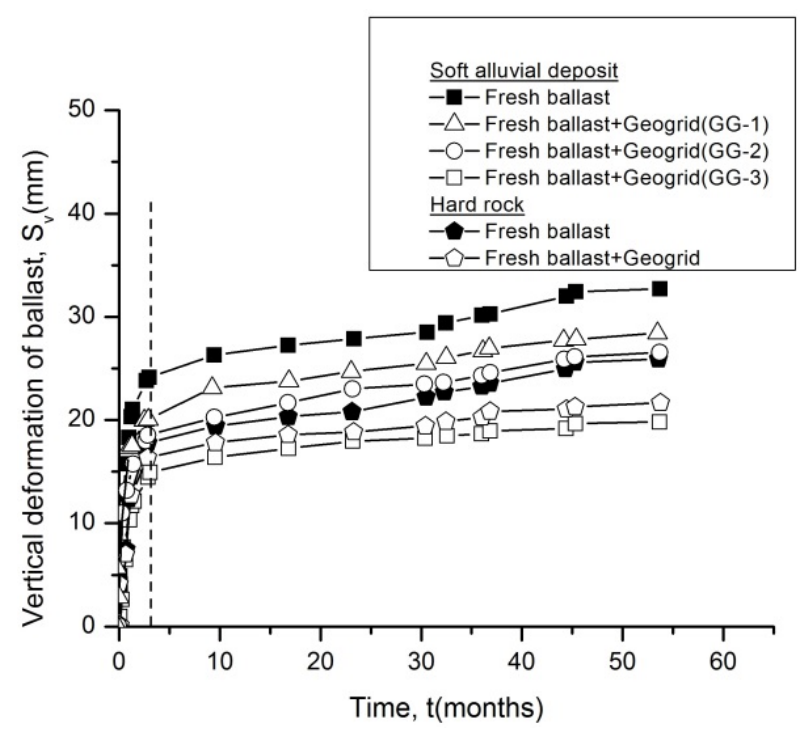

(a)

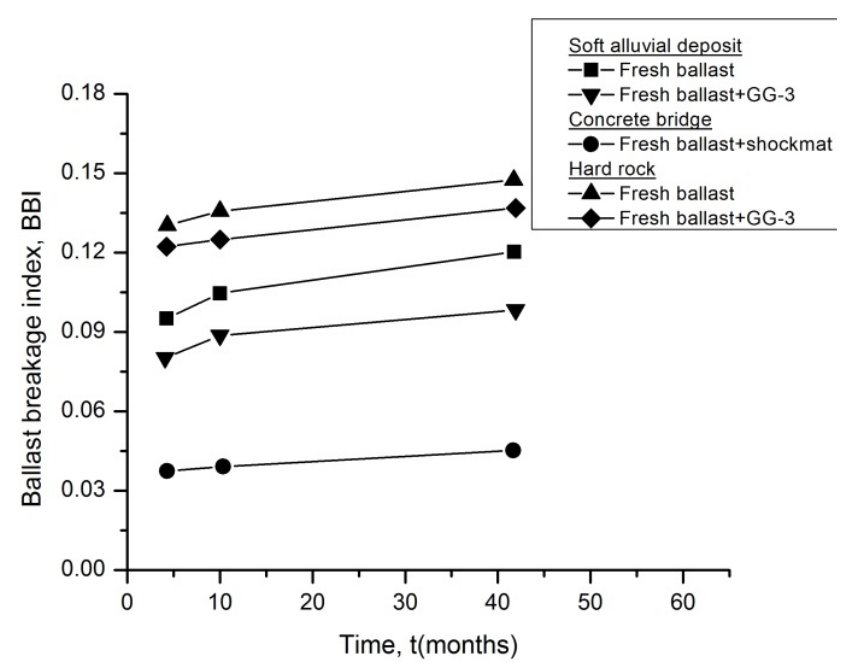

(b)

Figure 5. (a) Measured vertical settlements of ballast; (b) measured ballast breakage index, BBI (modified after Nimbalkar and Indraratna 2016 - with permission from ASCE).

\section{COMPUTATIONAL MODELING OF SCRAP TIRES-REINFORCED CAPPING}

The management of scrap tires is considered as one of the major environmental concerns in Australia, where every year more than 40 million waste tires are generated. Recently, research work carried out at the UOW has shown that these waste tires can be reused in the track foundation (Fig. 6a) to improve the performance of ballasted tracks by increasing the bearing capacity and reducing the lateral deformations (Indraratna et al. 2017). A 3D finite element analysis (Fig. 6b) was implemented in this study to examine the load-deformation response of a capping layer composed of gravel infilled rubber tires. Figure $6 \mathrm{c}$ presents the beneficial effect that rubber tires provide in terms of reduced deviator stresses at the surface of the subgrade. It is observed that the highest deviator stress occurs under the edge of the sleeper and then it decreases towards the middle of the sleeper. With the inclusion of tire-reinforcement, FEM simulations show almost a 12\% reduction compared to an unreinforced section (for the case of a 25 ton-axle load train running at a speed of $100 \mathrm{~km} / \mathrm{h}$ ). This is attributed to the additional confining effect provided by the tires that leads the gravel infill composite to become stiffer, which allows a decreased and more uniform stress to be transferred to the underlying subgrade. Figure $6 \mathrm{~d}$ shows the contours of lateral displacement that occur in the capping layer with and without recycled tires. A comparison of these contours shows that the maximum lateral displacement of the unreinforced capping layer is greater than that of the reinforced capping under similar loading conditions. It is therefore believed that the additional confinement provided by the rubber tires stiffens the capping layer and enables more uniform stress to be transmitted to the subgrade, with important implications on the stability of soft subgrades that may prematurely yield in the absense of adequate stress reduction provided by a reinforced capping layer. 


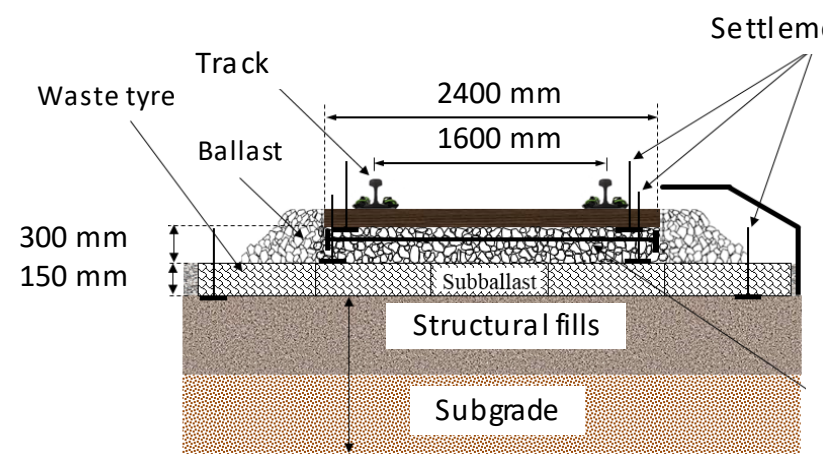

(a)

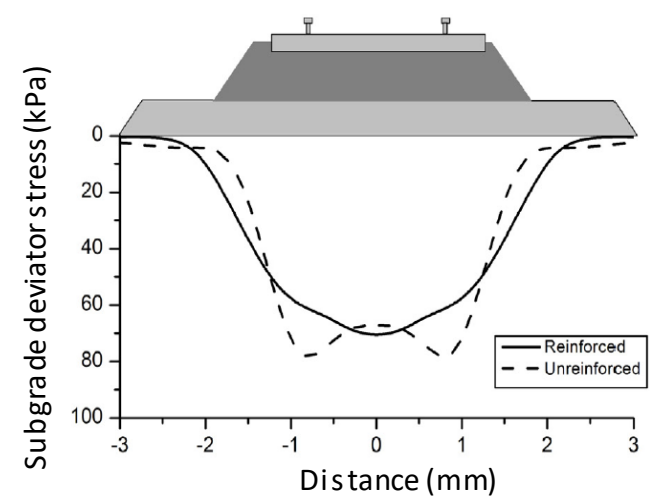

(c)

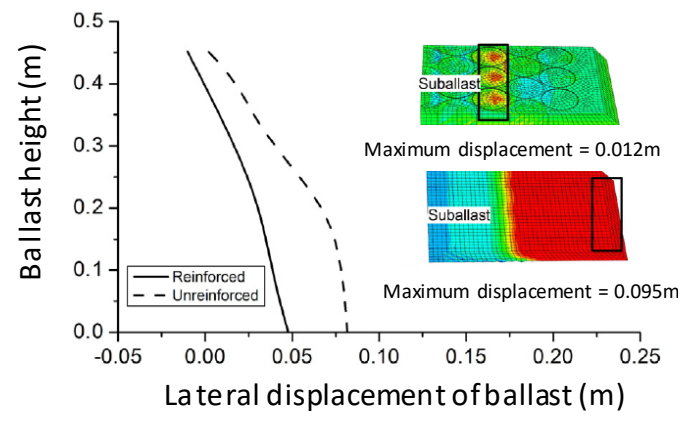

(d)

Figure 6: (a) Track geometry with rubber tires reinforced capping layer; (b) FEM mesh; (c) stress distribution below reinforced and unreinforced track; (d) simulated lateral displacement of ballast (modified after Indraratna et al. 2017).

\section{CONCLUSIONS}

This paper reviewed recent studies conducted at the UOW on the use of artificial inclusions for minimizing track deterioration induced by fast-moving heavy haul trains, based on extensive largescale experimental testing, full-scale field investigation and computational analysis. Key research findings on the stress-strain responses of ballast subjected to static, cyclic and impact loading, the use of synthetic inclusions, the degradation of ballast and its implications on track design and performance were discussed. It was noted that the normalized geogrid aperture ratio, $A / D_{50}$ had a significant influence on the interface efficiency parameter, $\alpha$. The best geogrid aperture size to optimize the interface shear strength was found to be about $1.2 D_{50}$. The field performance of ballasted rail tracks stabilized with artificial inclusions (geosynthetics and rubber mats) was also addressed in this paper. The results of the Bulli and Singleton field studies indicated that the use of geosynthetics as reinforcing elements for ballasted tracks can be a feasible and effective alternative. The installation of energy absorbing rubber mats beneath the ballast layer resulted in reduced ballast breakage, as inferred from the Singleton track measurements. Numerical simulation was carried out for a track model with and without the inclusion of recycled rubber tires in the capping layer and the obtained data indicated that the confinement provided by the scrap 
tires can decrease the magnitude of stresses transmitted to the underlying subgrade, which has pronounced implications on the stability and longevity of the track substructure.

\section{ACKNOWLEDGEMENTS}

This study was carried out by the ARC-Industrial Transformation Training Centre for Advanced Technologies in Rail Track Infrastructure (IC170100006) and funded by the Australian Government (ITTC-Rail). The authors appreciate the insightful collaboration and continuous support of the Australasian Centre for Rail Innovation (ACRI), Australian Rail Track Corporation (ARTC), Global Synthetics. The Authors sincerely acknowledge Rail Manufacturing Cooperative Research Centre (funded jointly by participating rail organisations and the Australian Federal Government's Business Cooperative Research Centres Program) through Project R2.5.2 that contributed some parts of this research. The authors gratefully acknowledge the efforts of past doctoral students and research fellows, including Dr Syed Hussaini, Dr Joanne Lackenby, Dr Qideng Sun and Dr Sanjay Nimbalkar, UOW technical staff, among others that have contributed to the contents, as cited in respective publications. Salient contents from these previous studies are reproduced herein with kind permission from the original sources.

\section{REFERENCES}

Abadi, Pen, L., Powrie. (2019). Effect of sleeper interventions on railway track performance. Journal of Geotechnical and Geoenvironmental Engineering, 145(4), 04019009.

Biabani, M.M., Ngo, T. and Indraratna, B. (2016). Performance evaluation of railway subballast stabilised with geocell based on pull-out testing. Geotextiles and Geomembranes, 44(4), 579-591.

Ferreira, F.B. and Indraratna, B. (2018). Deformation and degradation response of railway ballast under impact loading - effect of artificial inclusions. Proceedings of the $1^{\text {st }}$ International Conference on Rail Transportation, ICRT 2017, ASCE, 1090-1101.

Indraratna, B., Nimbalkar, S., Christie, D., Rujikiatkamjorn, C. and Vinod, J. (2010). Field assessment of the performance of a ballasted rail track with and without geosynthetics. Journal of Geotechnical and Geoenvironmental Engineering, 136(7), 907-917.

Indraratna, B., Ngo, N.T. and Rujikiatkamjorn, C. (2011). Behavior of geogrid-reinforced ballast under various levels of fouling. Geotextiles and Geomembranes, 29(3), 313-322.

Indraratna, B., Hussaini, S.K. and Vinod, J.S. (2012). On the shear behaviour of of ballastgeosynthetic interfaces. Geotechnical Testing Journal, 35(2), 1-8.

Indraratna, B., Nimbalkar, S. and Neville, T. (2014). Performance assessment of reinforced ballasted rail track. Proceedings of the ICE - Ground Improvement, 167, 24-34.

Indraratna, B., Nimbalkar, S.S., Ngo, N.T. and Neville, T. (2016). Performance improvement of rail track substructure using artificial inclusions - Experimental and numerical studies. Transportation Geotechnics, 8, 69-85.

Indraratna, B., Sun, Q. and Grant, J. (2017). Behaviour of subballast reinforced with used tyre and potential application in rail tracks. Transportation Geotechnics, 12, 26-36. 
Indraratna, B. and Ngo, T. (2018). Ballast Railroad Design: Smart-Uow Approach, CRC Press, Taylor \& Francis Group.

Indraratna, B., Ngo, N., Nimbalkar, S. and Rujikiatkamjorn, C. (2018). Two decades of advancement in process simulation testing of ballast strength, deformation, and degradation. Railroad Ballast Testing and Properties, ASTM STP1605: 1-28.

Kaewunruen, S. and Remennikov, A.M. (2009). Dynamic crack propagations in prestressed concrete sleepers in railway track systems subjected to severe impact loads. Journal of Structural Engineering, 136(6), 749-754.

Le Pen, L.M. and Powrie, W. (2011). Contribution of base, crib, and shoulder ballast to the lateral sliding resistance of railway track: a geotechnical perspective. Journal of Rail and Rapid Transit, 225(2), 113-128.

Lackenby, J., Indraratna, B., McDowell, G. and Christie, D. (2007). Effect of confining pressure on ballast degradation and deformation under cyclic triaxial loading. Géotechnique, 57(6), 527-536.

McDowell, G.R. and Li, H. (2016). Discrete element modelling of scaled railway ballast under triaxial conditions. Granular Matter, 18(3), 66.

Navaratnarajah, S.K., Indraratna, B. and Ngo, N.T. (2018). Influence of under sleeper pads on ballast behavior under cyclic loading: experimental and numerical studies. Journal of Geotechnical and Geoenvironmental Engineering, 144(9), 04018068.

Nimbalkar, S. and Indraratna, B. (2016). Improved performance of ballasted rail track using geosynthetics and rubber shockmat. Journal of Geotechnical and Geoenvironmental Engineering, 142 (8), 04016031.

Ngo, N.T., Indraratna, B. and Rujikiatkamjorn, C. (2017). A study of the geogrid-subballast interface via experimental evaluation and discrete element modelling. Granular Matter, 19(3), 54.

Ngo, N.T., Indraratna, B., Ferreira, F.B. and Rujikiatkamjorn, C. (2018). Improved performance of geosynthetics enhanced ballast: laboratory and numerical studies. Proceedings of the ICE - Ground Improvement, 171(4), 202-222.

Ngo, N., Indraratna, B. and Rujikiatkamjorn, C. (2019). Improved performance of ballasted tracks under impact loading by recycled rubber mats. Transportation Geotechnics, 20, 100239.

Powrie, W., Yang, L.A. and Clayton, C.R. (2007). Stress changes in the ground below ballasted railway track during train passage. Proceedings of the Institution of Mechanical Engineers: Part F: Journal of Rail and Rapid Transit, 221(2), 247-262.

Selig, E.T. and Waters, J.M. (1994). Track Geotechnology and Substructure Management, Thomas Telford, London.

Sun, Q., Indraratna, B. and Ngo, N.T. (2018). Effect of increase in load and frequency on the resilience of railway ballast. Géotechnique, DOI: https://doi.org/10.1680/jgeot.17.P.302.

Tutumluer, E., Huang, H. and Bian, X. (2012). Geogrid-aggregate interlock mechanism investigated through aggregate imaging-based discrete element modeling approach. International Journal of Geomechanics, 12(4), 391-398. 